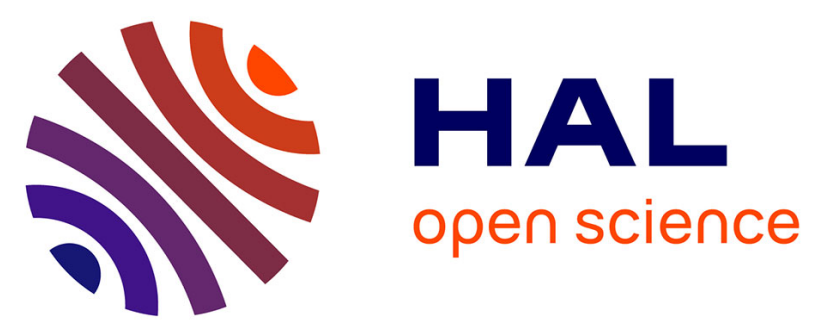

\title{
A few problems in the generic nomenclature of insects and amphibians, with recommendations for the publication of new generic nomina in zootaxonomy and comments on taxonomic and nomenclatural databases and websites
}

\author{
Alain Dubois
}

\section{To cite this version:}

Alain Dubois. A few problems in the generic nomenclature of insects and amphibians, with recommendations for the publication of new generic nomina in zootaxonomy and comments on taxonomic and nomenclatural databases and websites. Zootaxa, 2017, 4237 (1), pp.1-16. 10.11646/zootaxa.4237.1.1. hal-01510584

\author{
HAL Id: hal-01510584 \\ https://hal.sorbonne-universite.fr/hal-01510584
}

Submitted on 19 Apr 2017

HAL is a multi-disciplinary open access archive for the deposit and dissemination of scientific research documents, whether they are published or not. The documents may come from teaching and research institutions in France or abroad, or from public or private research centers.
L'archive ouverte pluridisciplinaire HAL, est destinée au dépôt et à la diffusion de documents scientifiques de niveau recherche, publiés ou non, émanant des établissements d'enseignement et de recherche français ou étrangers, des laboratoires publics ou privés. 
Article

A few problems in the generic nomenclature of insects and amphibians, with recommendations for the publication of new generic nomina in zootaxonomy and comments on taxonomic and nomenclatural databases and websites

\author{
Alain DUBOIS \\ Institut de Systématique, Évolution, Biodiversité, ISYEB - UMR 7205 - CNRS, MNHN, UPMC, EPHE, Muséum national d'Histoire \\ naturelle, Sorbonne Universités, 57 rue Cuvier, CP 30, F-75005, Paris, France.<adubois@mnhn.fr>.
}

\title{
Table of contents
}

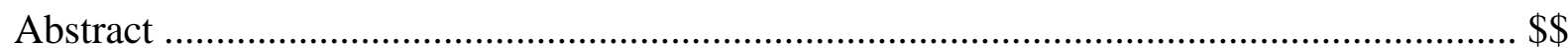

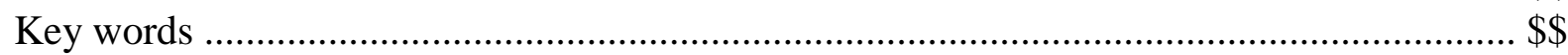

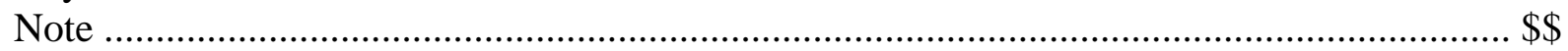

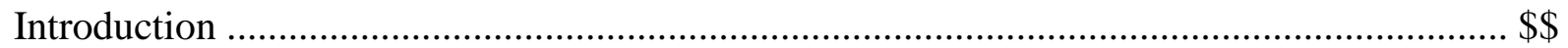

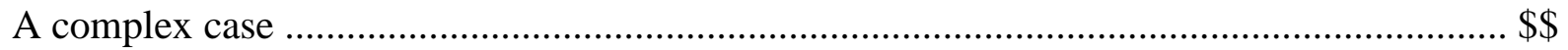

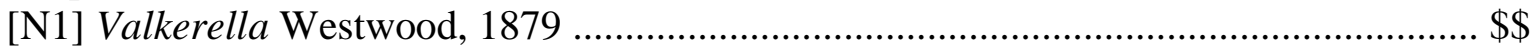

[N2] Walkerella Westwood, 1883 ................................................................................. \$

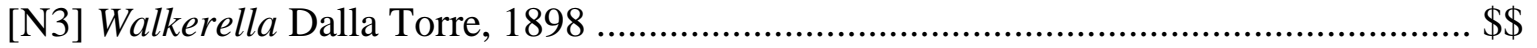

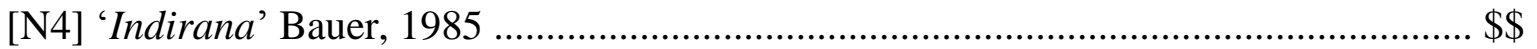

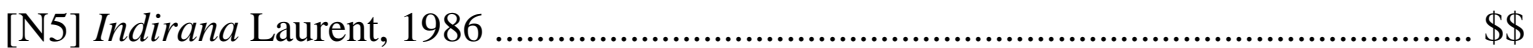

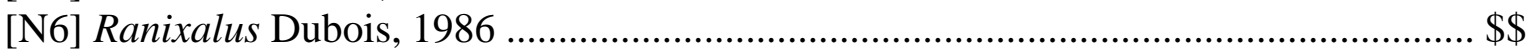

[N7] 'Walkerella' Otte \& Perez-Gelabert, 2009a ........................................................... \$ \$

[N8] 'Walkerana' Otte \& Perez-Gelabert, 2009b ............................................................ \$ \$

[N9] Walkerana Dahanukar, Modak, Krutha, Nameer, Padhye \& Molur, $2016 a$............. \$ \$

[N10] Sallywalkerana Dahanukar, Modak, Krutha, Nameer, Padhye \& Molur, 2016b .... \$\$

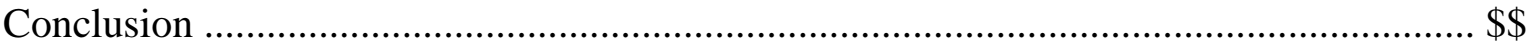

Recommendations for the publication of new generic nomina in zootaxonomy .................. \$\$

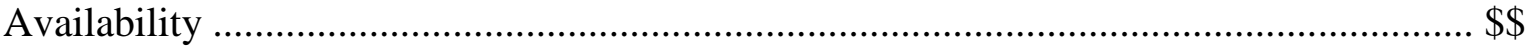

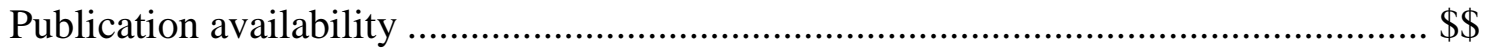

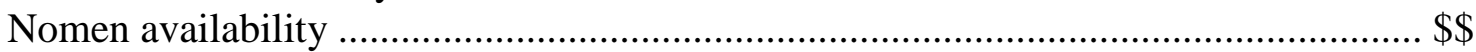

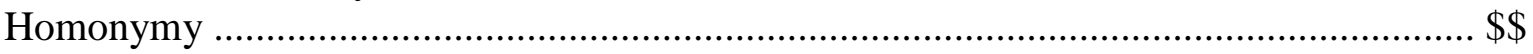

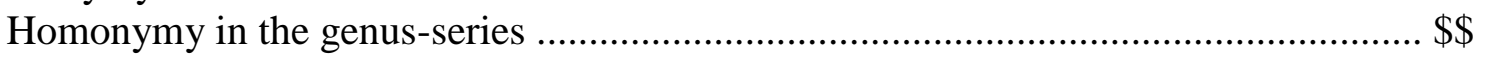

Homonymy in the family-series ...................................................................... $\$$

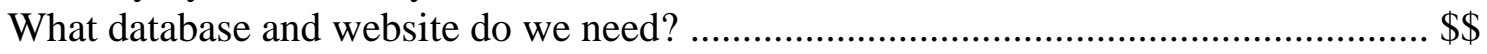

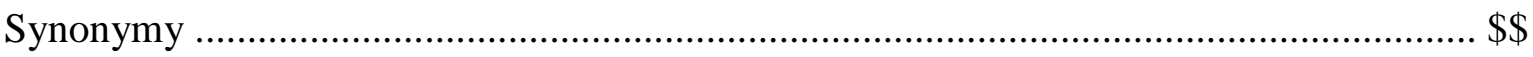

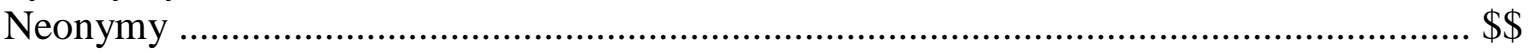

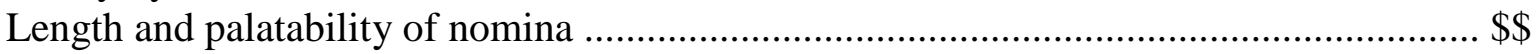

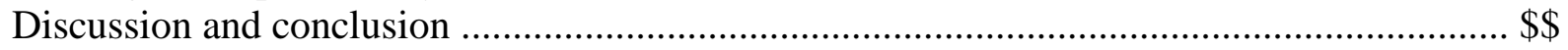

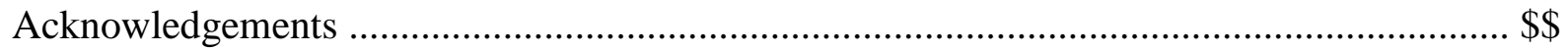

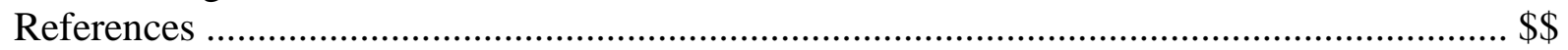




\begin{abstract}
.
Dahanukar et al. (2016a) proposed the nomen Walkerana for a new genus of amphibians, but shortly after $(2016 b)$ they replaced it by the new nomen Sallywalkerana, believing that their nomen Walkerana was preoccupied by a generic nomen of orthopterans. This was unjustified because the orthopteran nomen 'Walkerella' Otte \& Perez-Gelabert, 2009a and its new replacement nomen 'Walkerana' Otte \& Perez-Gelabert, $2009 b$ were both nomina nuda. These recent examples of nomenclatural errors in generic nomenclature are just a few among many in recent zootaxonomic publications. This opportunity is taken to make some general methodological recommendations, in several domains (availability, homonymy, synonymy, neonymy, length and palatability of nomina), for the publication of new generic nomina in zootaxonomy. However, the absence of a comprehensive database and website providing all the relevant information necessary to establish the nomenclatural status of all zoological generic and subgeneric nomina is a brake on the efforts that can be made to avoid nomenclatural errors in zoological generic nomenclature. The international community of taxonomists should seek at establishing such a database and website.
\end{abstract}

Key words. Nomenclatural errors, generic nomina, publication availability, nomen availability, homonymy, synonymy, nomen nudum, nomen novum, editors, review process, databases, websites.

\title{
Note
}

In this work like in all my works since Dubois (2005), the following typographical conventions are used for nomina (scientific names) according to their name group (Anonymous 1999) or better nominal-series (Dubois 2000): italics for species- and genus-series nomina, CAPITAL ITALICS for family-series nomina and BOLD CAPITALS for class-series nomina.

\section{Introduction}

Generic scientific names or nomina play a crucial role in zootaxonomy. They are the labels by which each specific nomen starts and they constitute a universal landmark in the classification of animal taxa, being intermediate between the species level and higher taxonominal ranks. They are used in all biological sciences in order to 'place' species in the tree of life and as a tool for retrieval of taxonomic information. Their stability is therefore very important and efforts should be made by taxonomists to facilitate this stability. One of the most efficient way to achieve it is to follow strictly the Code (Anonymous 1999) and to try to avoid nomenclatural errors when erecting new genera and proposing new nomina for them. In the recent decades, a rather high number of mistakes have been made in taxonomic publications introducing new nomina of the 'genus group' (Anonymous 1999) or better genus-series (Dubois 2000). Once published, these mistakes must be corrected in subsequent publications, which results in nomenclatural instability, sometimes very soon after a new nomen has been published. It is here suggested that this problem could be reduced, if not completely eliminated, if taxonomists followed a methodology allowing to avoid the possible nomenclatural 'traps' that may appear during the nomenclatural act consisting in publishing a new genus-series nomen. Such a methodology is proposed here. In order to show concretely the kind of problems that may occur during this process, a rather complicated case involving ten generic nomina including several recent ones is analysed first in detail, then generalisations are presented. 


\section{A complex case}

A rather complex nomenclatural situation concerns ten zoological generic nomina, in three different zoological groups (HYMENOPTERA, ORTHOPTERA, ANURA), which are connected by homonymy and neonymy (relationship between new replacement nomina or neonyms and the nomina they replaced or archaeonyms; see Dubois 2000, 2006). They are presented below in the chronological order of their publication. For each of them, two websites, namely the online version of the Nomenclator Zoologicus [http://uio.mbl.edu/NomenclatorZoologicus/] and Zoobank [http://zoobank.org/], were surveyed in order to see whether and which, if any, information was provided about it on 5 October 2016.

\section{[N1] Valkerella Westwood, 1879}

Westwood (1879: 584, foonote) proposed conditionally the genus nomen Valkerella for Polynema natans Lubbock, 1864, a species of chalcidids (INSECTA, HYMENOPTERA). Both these nomina are nomenclaturally available and currently considered invalid synonyms of nomina of taxa referred to the family MYMARIDAE Haliday, 1833, respectively of Caraphractus Walker, 1846 and of Caraphractus cinctus Walker, 1846 (see e.g. Yoshimoto 1990).

According to Huber (2005: 175), this genus was named after Francis Walker (1809-1874), who worked at the British Museum (Natural History) of London. The letter W was absent in classical Latin, so Westwood replaced it by the letter V. Whether this should be considered or not as an incorrect latinisation is opened to question (it would not with regard to classical Latin, but it would in modern Latin) but is irrelevant from a nomenclatural point of view, as according to Article 32.5.1 an incorrect latinisation is not to be considered as inadvertent error. The original spelling of this nomen is therefore its "correct original spelling" and it should not be modified.

As of 5 October 2016, the nomen Valkerella Westwood, 1879 was duly mentioned in Neave (1940: 627) and, by way of consequence, in the online version of the Nomenclator Zoologicus. However, it did not appear in the website Zoobank.

\section{[N2] Walkerella Westwood, 1883}

Westwood (1883: 32) erected a genus Walkerella for a single new species of chalcidid hymenopteran, Walkerella temeraria, which he designated as 'typus' of this genus. Both nomina are nomenclaturally available and currently considered valid to designate taxa of the family PTEROMALIDAE Dalman, 1820 (see e.g. Heraty et al. 2013).

As of 5 October 2016, the nomen Walkerella Westwood, 1883 was duly mentioned in Neave (1940: 651) and, by way of consequence, in the online version of the Nomenclator Zoologicus. It did not appear as such in the website Zoobank, but a publication using this nomen (Ma et al. 2013) was cited as having been registered in this website. 


\section{[N3] Walkerella Dalla Torre, 1898}

Dalla Torre (1898: 425) incorrectly considered that the original spelling of the nomen Valkerella Westwood, 1879 was incorrect and proposed the spelling Walkerella expressly as an emendation or autoneonym (Dubois 2000) of the latter. As noted by Huber (2005: 176), this is an unjustified emendation, and as such it is nomenclaturally available with its own author and date but is invalid both for being a junior objective synonym of the latter and a junior homonym of Walkerella Westwood, 1883.

As of 5 October 2016, the nomen Walkerella Dalla Torre, 1898 was not mentioned in Neave (1940: 651) and, by way of consequence, it was also absent in the online version of the Nomenclator Zoologicus. It did not appear either in the website Zoobank, which however provided a link to its mention in the website Ubio Name Bank [http://www.ubio.org/], where it appeared incorrectly as a valid generic nomen referred to the family MYMARIDAE.

\section{[N4] 'Indirana' Bauer, 1985}

Bauer (1985: 7, N7) proposed the new nomen 'Indirana' for a new genus of frogs (AMPHibia, ANURA) from India for which he designated the nominal species Rana leptodactyla Boulenger, 1882 as 'type species'. However, he did not provide any diagnostic character for this genus, so that his new nomen is a nomen nudum, nomenclaturally unavailable (see Dubois et al. 2016).

As of 5 October 2016, the nomen 'Indirana' Bauer, 1985 was mentioned neither in the online version of the Nomenclator Zoologicus nor in Zoobank, but the latter provided a link to its mention in the website Index to Organism Names [http://www.organismnames.com/], where however no information of nomenclatural relevance (e.g., original reference or statement that it is a nomen nudum) was provided about it except for its existence.

\section{[N5] Indirana Laurent, 1986}

Laurent (1986: 761) proposed the new nomen Indirana for a new genus of frogs (AMPHIBIA, ANURA) from India for which he designated the nominal species Polypedates beddomii Günther, 1876 as 'type species'. The nomen of this genus is not preoccupied by 'Indirana' Bauer, 1985, as the latter nomen is nomenclaturally unavailable.

As of 5 October 2016, the nomen Indirana Laurent, 1986 was mentioned in the online version of the Nomenclator Zoologicus, with its original reference. It was also cited in Zoobank, but without its original reference.

\section{[N6] Ranixalus Dubois, 1986}

Dubois (1986: 114) described the new frog genus Ranixalus and its type and unique species Ranixalus gundia from India. Shortly after, Dubois (1987a: 66-67) referred to this genus several species previously placed by Boulenger (1920) in his group 'Ranae beddomianae' of the genus Rana, including the nominal species Polypedates beddomii Günther, 1876 and Rana 
leptodactyla Boulenger, 1882. Finally, Dubois (1987b: 175) pointed to the priority of Indirana Laurent, 1986 over Ranixalus Dubois, 1986, published a few months later.

As of 5 October 2016, the nomen Ranixalus Dubois, 1986 was mentioned in the online version of the Nomenclator Zoologicus but did not appear in Zoobank.

\section{[N7] 'Walkerella' Otte \& Perez-Gelabert, 2009a}

The book of Otte \& Perez-Gelabert (2009a) on gryllids (INSECTA, ORTHOPTERA) is a cornucopia of taxonomic and nomenclatural problems, but let us concentrate here on one of them. These authors $(2009 a$ : [iii], 221, 257) proposed the new generic nomen 'Walkerella' for a genus from the Dominican Republic, in which they described ten new species, one of which, Walkerella enstates, was designated as type species of this genus. For this species, they provided a very poor diagnosis mentioning a few measurements and a single character of difference in the male genitalia between this species and their new species Walkerella timens ("aedeagus is distinctly shorter in ventral view") but no difference with the other eight species they recognised in this genus; however, as a few measurements were given, these can be accepted as an idiognosis of the species (see Dubois \& Raffaëlli 2009: 15) and this species nomen as nomenclaturally available. However, the only 'diagnosis' they provided for the genus 'Walkerella' itself is as follows: "This genus is distinguished from related genera mainly by the configuration of the male genitalia". Such a statement is not enough to make a new nomen available, as it does not comply with the requirements of Article 13.1.1 of the Code (Anonymous 1999) which states that "every new name published after 1930 (...) must (...) be accompanied by a description or definition that states in words characters that are purported to differentiate the taxon". In this sentence, the word 'character' is not defined, but in the 'Glossary' of the Code the following definition is provided: "character, n. Any attribute of organisms used for recognizing, differentiating, or classifying taxa". With such a definition, the term 'character' can be used appropriately to provide nomenclatural availability in two situations: [S1] to distinguish specimens that have a given feature (e.g., a tail, a tympanum, a gland) from those who lack it; [S2] to distinguish various avatars of this feature when present (e.g., a short tail vs. a long tail). In both cases, what is at stake is not really the character itself (e.g., the colour, the size, the tail) but the state of character or signifier (Ashlock 1985). Thus, stating that two species differ by their colour, size or tail does not provide nomenclatural availability, but stating that the colour of one of two species is blue and that of the other red, or that one species is larger than $50 \mathrm{~mm}$ and the other one smaller than $20 \mathrm{~mm}$, or that one has a long tail and the other one a short one, does. Therefore, stating that two taxa differ by the form of their genitalia without stating how their genitalia differ is not enough to provide nomenclatural availability to a nomen. The simple mention of a figure where this difference is supposed to be 'evident' does not change this situation, as Article 13.1.1 precises very clearly "states in words". There is in the work of Otte \& Perez-Gelabert (2009a) no other information on the purported diagnostic characters of the genus 'Walkerella' in all the other mentions of this nomen in this book (p. [iii], 221, 257, 792), including in the 'key' to the 'Orocharis group' of the tribe HAPITHINI Gorochov, 1986 (p. 221) where diagnostic characters are given for some genera only. In conclusion, the nomen 'Walkerella' Otte \& Perez-Gelabert, $2009 a$ is a nomen nudum (unavailable nomen for failing to comply with Article 13.1.1).

As of 5 October 2016, the nomen 'Walkerella' Otte \& Perez-Gelabert, 2009a was mentioned neither in the online version of the Nomenclator Zoologicus nor in Zoobank, which however 
provided a link to its mention in the website Orthoptera Species File [http://orthoptera.speciesfile.org/]. The latter did not state that it is a nomen nudum but treated it as invalid for being preoccupied by Walkerella Westwood, 1883.

\section{[N8] 'Walkerana' Otte \& Perez-Gelabert, 2009b}

Otte \& Perez-Gelabert (2009b: 488) stated that they had been informed of the existence of the nomen Walkerella Westwood, 1883, and consequently proposed the new replacement nomen 'Walkerana' for their nomen 'Walkerella' Otte \& Perez-Gelabert, 2009a, not realising that the latter was a nomen nudum. They still did not provide a diagnosis for this genus. Being a nomen novum for an unavailable nomen, 'Walkerana' Otte \& Perez-Gelabert, 2009b is itself a nomen nudum and cannot be used as valid.

As of 5 October 2016, the nomen 'Walkerana' Otte \& Perez-Gelabert, $2009 b$ was mentioned neither in the online version of the Nomenclator Zoologicus nor in Zoobank.

\section{[N9] Walkerana Dahanukar, Modak, Krutha, Nameer, Padhye \& Molur, 2016a}

Dahanukar et al. (2016a: 9221, 9234) erected the new genus Walkerana for three frog species: Ixalus diplostictus Günther, 1876 (designated as its 'type species'), Rana leptodactyla Boulenger, 1882 and Rana phrynoderma Boulenger, 1882. This new generic nomen is not preoccupied by 'Walkerana' Otte \& Perez-Gelabert, $2009 \mathrm{~b}$ as the latter is nomenclaturally unavailable.

These authors considered this new genus as the sister-group of the genus Indirana Laurent, 1986, in which they recognised 11 species, including those originally described as Polypedates beddomii Günther, 1876 (type species of Indirana Laurent, 1986) and Ranixalus gundia Dubois, 1986 (type species of Ranixalus Dubois, 1986). Interestingly, if this generic taxonomy is adopted as valid, the unavailable nomen 'Indirana' Bauer, 1985, the type species of which is Rana leptodactyla Boulenger, 1882, must stand in the synonymy of Walkerana Dahanukar et al., 2016a, not of Indirana Laurent, 1986.

As of 5 October 2016, the nomen Walkerana Dahanukar et al., 2016a was not mentioned in the online version of the Nomenclator Zoologicus but it was so in Zoobank, with its original reference.

\section{[N10] Sallywalkerana Dahanukar, Modak, Krutha, Nameer, Padhye \& Molur, 2016b}

Dahanukar et al. (2016b: 9381), having been informed of the existence of the nomen 'Walkerana' Otte \& Perez-Gelabert, 2009b, thought that their nomen Walkerana Dahanukar et al., 2016a was preoccupied by the latter, and proposed the nomen Sallywalkerana as a nomen novum for the frog generic nomen. However, as shown above, this was neither necessary nor justified, as 'Walkerana' Otte \& Perez-Gelabert, $2009 b$ is nomenclaturally unavailable. Therefore Sallywalkerana Dahanukar et al., $2016 b$ is an invalid junior objective synonym of Walkerana Dahanukar et al., 2016a, and the three species referred to the latter genus should keep the binomina coined for them by Dahanukar et al. (2016a). This is 
fortunate, because the nomen Walkerana is long enough for a generic nomen, and Sallywalkerana is doubtless unnecessarily long and can be considered unpalatable by many (see Dubois 2010: 14-18).

As of 5 October 2016, the nomen Sallywalkerana Dahanukar et al., 2016b was not mentioned in the online version of the Nomenclator Zoologicus but it was so in Zoobank, with its original reference.

\section{Conclusion}

The ten generic nomina discussed above refer to five distinct generic taxa. Their current statuses are as follows:

[T1] The generic nomen [N1] Valkerella Westwood, 1879 and its autoneonym [N3] Walkerella Dalla Torre, 1898 are available and currently considered invalid junior subjective synonyms of Caraphractus Walker, 1846 (INSECTA, HYMENOPTERA).

[T2] The generic nomen [N2] Walkerella Westwood, 1883 (INSECTA, HyMENOPTERA) is available and currently considered valid.

[T3] Both generic nomina [N7] 'Walkerella' Otte \& Perez-Gelabert, 2009a and [N8] 'Walkerana' Otte \& Perez-Gelabert, 2009b (InSECTA, ORTHOPTERA) are nomenclaturally unavailable. Therefore, if the genus for which they were proposed is to be recognised as valid, and if no other available nomen exists that would apply to this genus, a generic nomen must be proposed for it.

[T4] The generic nomen [N5] Indirana Laurent, 1986 (AMPHIBIA, ANURA) is available and currently considered valid, and the nomen [N6] Ranixalus Dubois, 1986 its invalid junior subjective synonym.

[T5] If the classification proposed by Dahanukar et al. (2016a) is adopted, the available generic nomen [N9] Walkerana Dahanukar et al., 2016a (AMPHIBIA, ANURA) must be treated as valid, with one senior unavailable subjective synonym [N4] 'Indirana' Bauer, 1985 and one junior invalid objective synonym, [N10] Sallywalkerana Dahanukar et al., $2016 b$.

\section{Recommendations for the publication of new generic nomina in zootaxonomy}

Many new animal genera and subgenera are described and named each year. Unfortunately, each year some of these new nomina (in an unknown proportion, as this matter does not seem to have been explored so far) are soon invalidated, sometimes for very trivial reasons, such as failure to have been published in a way complying with the requirements of the Code regarding nomenclatural availability, or for being junior homonyms of available generic nomina, or junior synonyms of available generic nomina that had not been taken in consideration, or for rarer causes such as two of those illustrated above (nomen being a neonym for an unavailable nomen, or a useless neonym for a nomen that had been considered by error to be invalid). Although a small proportion of such errors are almost inevitable due to the incompleteness or difficult accessibility of the nomenclatural information (e.g., because 
some generic nomina are missing in the Nomenclator Zoologicus), most of them could probably be avoided if authors of taxonomic papers followed a strict and reliable methodology before proposing new genus-series nomina. A brief outline of such a methodology is presented below.

Of course, the first condition for publishing new genus-series nomina is to rely on clear and solid taxonomic concepts and data, and this should briefly appear here as the first relevant recommendation here. Nowadays, the requirement that taxonomy should more or less accurately 'reflect phylogeny' is widely shared, and it is not arguable to erect new genera when the data clearly point to such taxa being paraphyletic or polyphyletic. But it is not enough to state that genera should be 'monophyletic' (sensu Hennig 1950) or holophyletic (Ashlock 1971), because this requirement equally applies to all supraspecific taxa: so this condition alone does not allow to support the decision to afford to such taxa the rank genus rather than another rank (species group, subgenus, subtribe, tribe, subfamily, family, etc.). As there exists currently no generally accepted 'concept of genus' throughout zoology (see e.g. Dubois 1988, 2004), the treatment of supraspecific taxa as 'genera' can only rely on a more or less general 'consensus' among authors working on the zoological group at stake, so that genera in different zoological groups are in no way 'equivalent' in phenetic, genetic, biological, historical or other terms (Dubois 1988, 2011a). But the widely accepted requirement that taxonomy of the $21^{\text {st }}$ century be 'phylogenetic' has at least one consequence: within a given group or 'clade', taxa that are considered to be 'sister-taxa' according to the phylogenetic hypothesis adopted as valid should always be afforded the same rank (Dubois 2008). This is the only way for nomenclatural ranks to be informative and to help for the transcription of a tree into a taxonomic hierarchy. This means that classifications like those illustrated in tables 5 and 9 of Dubois (2008) should not be accepted —or that ranks should be abandoned altogether, for being meaningless and useless in zootaxonomy, as suggested by some (see e.g. the references cited in Dubois 2011b: 53).

This being said, if the taxonomic conditions for erecting a new genus or subgenus are considered to be fulfilled, when it comes to naming this taxon a number of precautions should be taken to avoid nomenclatural problems. Special care should be taken in several domains (availability, homonymy, synonymy, neonymy, length and palatability of nomina). These precautions can be summarised as follows.

\section{Availability}

Two kinds of conditions should be respected for a new nomen to be made nomenclaturally available in a publication: those concerning the publication and those concerning the nomen itself.

\section{Publication availability}

The Rules concerning the nomenclatural availability of publications are presented in Articles 7-9 of Chapter 3 of the Code, which should be consulted in this respect. Articles 8-9 were recently modified in the 2012 Amendment of the Code (Anonymous 2012). The Rules concerning paper publications were only very slightly modified, but important changes were brought to the Code concerning electronic publications. Until 31 December 2011, electronic publications could not provide nomenclatural availability, but after that date they may provide 
such availability, provided several stringent conditions are complied with: [C1] the work must have been published as widely accessible electronic copies with fixed content and layout; [C2] the publication date must be stated in the work itself; [C3] the work must have been registered in Zoobank, this registration having been made prior to its publication, and evidence for this registration must appear in the work itself; [C4] the entry in Zoobank must include several pieces of information listed in Article 8.5.3 of the 2012 Amendment.

Publications that do not comply with any of these conditions are not nomenclaturally available and therefore the new nomina and/or nomenclatural acts they may contain are also unavailable. Various possibilities for unavailability of electronic publications were listed in Dubois (2015: 83-84) and in Dubois \& Aescht (2016: 62-64). They include: [P1] 'preliminary versions' of works accessible electronically in advance of publication of the 'final version' (Articles 9.9, 21.8.3); [P2] all kinds of 'Supplementary Information' published online as an addition to a work published on paper, or online but as a document distinct from the paper registered in Zoobank itself; and [P3] facsimiles and reproductions obtained "on demand" of a work deemed to be unpublished under Article 8, "even if previously deposited in a library or other archive" (Article 9.12). Dubois et al. (2013) published a long list of electronic publications which are unavailable for failing to have respected some of the conditions above, and of new nomina introduced in these works that are consequently unavailable themselves. Many other works showing similar errors have been published since then. Given the importance of the problems regarding the nomenclatural availability of electronic publications that have appeared since 2012, it is quite likely that the 2012 Amendment will have to be amended again. In the meanwhile, zootaxonomists should care for following scrupulously the Rules of this amendment.

An even more prudent and wise approach is to choose for the publication of new nomina and/or nomenclatural acts only journals that are published simultaneously on paper and online, or only on paper. This recommendation is in line with the following one which is part of the 'General recommendations' given in Appendix B of the Code (p. 126), that was not modified or suppressed in the 2012 Amendment: "New names should be established in a work which is printed on paper, which is self-evidently published in the meaning of the Code and has a wide circulation, and which zoologists would not regard as unlikely to contain new names in the taxonomic field concerned."

\section{Nomen availability}

Regarding the Rules of nomenclatural availability of new nomina, they are listed in Chapter 4 of the Code, which should be consulted in this respect. For works published after 1999, particular attention should be paid to Articles 13 and 16.

For example, for the availability of any new nomen published after 1930, Article 13.1 requires that it "be accompanied by a description or definition that states in words characters that are purported to differentiate the taxon", or by a reference to such a published statement, or be proposed expressly as a neonym for an available nomen (therefore a neonym proposed for an unavailable nomen is itself unavailable; see e.g. the case of the nomen [N8] above). The phrase "states in words characters" should be taken literally: it means that a nomen cannot be made available by a coinognosis (Dubois \& Raffaëlli 2009: 15), i.e. by simple mention of the position of a taxon in a tree (see e.g. the references cited by Ohler \& Dubois 2012: 165), or by simple reference to a photograph, if not accompanied by a verbal description of the diagnostic 
characters of the taxon which the photograph is supposed to show (see e.g. the case of the nomen [N7] above).

Article 13.3 states that a generic or subgeneric nomen published after 1930 must be accompanied by the designation of a type species in the original publication or be expressly published as a neonym.

Article 16.1 states that every new nomen published after 1999, including neonyms, must be explicitly indicated as intentionally new.

Any new nomen that fails to comply with a single relevant Rule of Chapter 4 (as partially amended in 2012) is nomenclaturally unavailable and therefore cannot be used as valid in zootaxonomy. Among the 10 nomina addressed above, three are in this situation: [N4], [N7] and [N8]. If the taxon for which such a nomen was introduced is to be recognised as valid, a new generic nomen must be proposed for it — unless an available nomen already exists for this purpose, e.g. 'hidden in a synonymy', a rather frequent situation indeed in zoological nomenclature.

\section{Homonymy}

The Code forbids the simultaneous existence in zoological nomenclature of two identical nomina or, in the species- and family-series, of two nomina 'deemed to be identical' according to the conventions of the Code. In case of homonymy, except in a few particular cases, the junior homonym(s) is/are invalid, even if the senior homonym is itself invalid for some other reason. Therefore, whenever a new nomen is proposed, it is crucial to ascertain that it is not a junior homonym of an already available nomen, which would make the new nomen invalid as soon as it is published. To avoid this inconvenience, authors, referees and editors of taxonomic papers should be aware of this potential problem and should try to avoid it.

\section{Homonymy in the genus-series}

The situation is particularly clear and easy to handle in the case of the genus-series (generic and subgeneric nomina), as for these nomina homonymy is limited to strict homography, i.e. absolute identity in spelling: even if the difference between two such nomina is only one letter, they are not homonyms according to Article 56.2. Another favorable particularity of genus-series nomina is that there exists for them a 'close-to-complete' list of the nomina published since 1758 for new genera and subgenera of all zoological groups, the Nomenclator Zoologicus - whereas no such comprehensive lists exist for species-, family- and class-series nomina. Therefore, before publishing a new genus-series nomen, any zootaxonomist has the possibility, and indeed should, consult this list to try to avoid the publication of junior homonyms.

Unfortunately, the Nomenclator Zoologicus offers only a partial solution to this problem. This nomenclator, which followed previous ones (particularly those of Louis Agassiz and Charles Davies Sherborn), was first published, from 1939 onwards, by the Zoological Society of London in a series of ten books initially edited by Sheffield Airey Neave and usually designated collectively as 'the Neave'. The content of these books is now available online 
[http://uio.mbl.edu/NomenclatorZoologicus/] under the subtitle 'A list of the names of the genera and subgenera in zoology from the tenth edition of Linnaeus 1758 to the end of 2004'. As this subtitle indicates, this list has not yet been updated after 2004, so that trusting it as being 'complete' may lead to publish junior homonyms of genus-series nomina made available in 2005 onwards. Besides, even for the years covered by this database, the information provided is far from being complete and always accurate, many generic nomina missing altogether, whereas some of the information it contains is wrong and should be corrected (see e.g. Alonso-Zarazaga \& Lyal 1999: 266-269).

A complement to the Nomenclator Zoologicus may in some cases be provided by the website Zoobank [http://zoobank.org/], established and cared for by the International Commission on Zoological Nomenclature ('the Commission' below). This site provides information on some zoological nomina but it is much more incomplete than the Nomenclator Zoologicus, for a very simple reason: because of lack of funds, the filling of its database is left to the voluntary contribution of individual zoologists. As the 2012 Amendment of the Code made compulsory the registration of works published electronically for the nomenclatural availability of the new nomina and nomenclatural acts they contain, the authors of such works progressively enter their new nomina on this site, and on this occasion they sometimes also enter more ancient nomina of the same taxonomic group. If these conditions do not change, i.e., if there is no program and budget for the professional filling of this database, e.g. first through entering all the contents of the Nomenclator Zoologicus, this database will remain for many years or decades highly incomplete, and therefore unreliable, for taxonomists planning to publish new generic nomina and wishing to avoid the creation of junior homonyms.

If we consider the ten nomina examined above, one of them only is mentioned both in the Nomenclator Zoologicus and in Zoobank, three are present in the former only, two in the latter only and four in none of them. Furthermore, for four nomina absent as such in Zoobank, links are provided to references of works where they are mentioned. However, even when a nomen is mentioned in one of these websites, the information that it is a nomen nudum, a junior homonym or a neonym is sometimes missing (see above for details). Therefore, even with a combined use of these two websites, it would have been impossible for an uninformed taxonomist to be aware of the existence of all these ten nomina, or of some aspect of their status (e.g., being nomina nuda), and therefore to be sure to avoid the publication of junior homonyms. The same would apply to any planned proposal of a new genus-series nomen.

Many other taxonomic and/or nomenclatural online databases exist, some of which are cited above in relation with some of these ten nomina, but they are of very limited nomenclatural usefulness as none of them provides comprehensive information on these nomina, such as the original reference of their first publication, whether they are available or unavailable, not to mention their type species with its mode of designation, although the latter information is of the utmost importance to establish the taxonomic status of a nomen. In the paper version of the first volumes of the paper version of the Neave nomenclator, some important information was provided on some nomina, such as the mentions ' $[n . n$.]' for nomina nuda, 'emend. pro' for emendations, 'pro' for nomina nova, 'nec' for homonyms or 'as' for alternative original spellings, but none of these pieces of information is given in Zoobank, and it is unclear whether these will be included in the Nomenclator Zoologicus for the new genus-series nomina published after 2004 if and whenever the latter is updated. In order to be able to incorporate this information in a website, it is not sufficient to enter the information that a given nomen 'exists', and to mention its place in a taxonomic hierarchy, it is also necessary to be able to analyse its nomenclatural status, a work that can be done correctly only by fully 
competent taxonomists - which many of the people who enter references, nomina and other data into Zoobank are far from being. Without (a) consistent 'moderator(s)' checking, correcting and completing this 'rough' information, this website will remain of very restricted usefulness to taxonomists and less reliable than the Nomenclator Zoologicus for the nomina the latter contains.

Today, the recourse to the Nomenclator Zoologicus, complemented for the recent years by Zoobank, can avoid the creation of many junior homonyms, but it is not a universal panacea, as both databases are incomplete. A possible complement to these two databases can be obtained by surveying (on paper or online) all the post-2004 volumes of the 'List of new generic and subgeneric names' published yearly in the Zoological Record. Another approach is to carry out a search for the contemplated new nomen by means of a search engine: the absence of any result is a rather good indication that no such nomen with the same spelling probably already exists. None of these 'solutions' is perfect, as some rarely mentioned nomina may escape all these searches and surveys, but such precautions can largely reduce the risk of publishing new junior homonyms in the genus-series.

\section{Homonymy in the family-series}

A last recommendation concerning homonymy concern family-series nomina. The latter are normally coined by adding a suffix indicating plural to the stem of a genus-series nomen. Different, non-homonymous genus-series nomina may have identical or homonymous stems (e.g., the stem of both Caecilia Linnaeus, 1758 and Caecilius Curtis, 1837 is Caecili-), so that family-series based on them must be considered homonyms, even if they have different endings. To avoid the creation of such family-series rhizomonyms (Dubois 2012), it is advisable not to coin a new genus-series nomen having the same stem as another available nomen already existing. Even if Article 29.6 of the current Code now allows to avoid such homonymy when coining a new family-series nomen by affording it an appropriate stem (e.g., by using the entire generic nomen as the stem of the family-series nomen), this solution is an awkward one, as it often results in longer, unpalatable nomina, the unusual derivation of which is not easy to guess by taxonomists. It is therefore better to avoid creating the conditions for such a situation by following the advice given above.

\section{Which database and website do we need?}

Rather than having a multitude of taxonomic and/or nomenclatural websites, most of which are incomplete and filled with mistakes, what would be really useful to the community of taxonomists would be a single website gathering, after correction of the errors, all the nomenclatural information spread over these various individual projects.

In this respect, it is useful to distinguish two aspects in the 'status' of a nomen: its nomenclatural and its taxonomic status.

The nomenclatural status of a nomen consists in all the elements of the status of the nomen that do not depend on the classification adopted as valid: its original reference, author and date; whether the nomen is available or not; its correct original spelling; whether it is a junior homonym or objective synonym of another nomen; its onomatophore ('type' specimen(s), species or genus); and whether it has been the matter of a decision of the Commission under 
its Plenary Powers. Most of these elements are fixed in the original work where the nomen is first published, but a few may be fixed subsequently by first-reviser actions aiming at removing ambiguities (e.g., fixation of correct original spelling among multiple original spellings or subsequent designation of onomatophore) or by exceptional action of the Commission. These data can be entered in a database and, in many cases, they will not change subsequently. They are the solid basis on which the taxonomic status of the nomen (i.e., its allocation and validity) will rely and they will be the basis on which nomenclatural decisions and acts will be based (e.g., the need to replace a junior homonym by a neonym if no other nomen is available for a taxon).

In contrast, the taxonomic status of a nomen is much more labile, as it will depend on the classification adopted by an author and therefore on which taxa are considered valid and need to be named. In most cases, this process of naming is automatic and depends only on the application of the Rules, including if necessary the need of nomenclatural first-reviser actions. Building a database including taxonomic information, i.e. stating which taxa are valid and which are their hierarchical relations, is much more complex, time and energy consuming than building a nomenclatural database, simply because in most zoological groups there is not one but several competing classifications at any given time of the history of the taxonomy of the group (see e.g. Minelli 1991). Building such a database therefore requires either to make choices among competing classifications, or showing all of them. The choice may be made simply by showing the 'most recently published' (which is poorly justified theoretically, as the 'last' classification is not always the best one, and which anyway requires permanent updates) or to make subjective decisions according to the opinions of the manager or author of the database. The latter solution is adopted in most existing databases. In some of them, such as Amphibian Species of the World [http://research.amnh.org/vz/herpetology/amphibia/re needed], the author of the database may even indulge him/herself to introduce his/her own ideas and comments, and although the latter have not gone through any process of scientific publication and the database is not submitted to any kind of peer-review, these are sometimes considered to be authoritative by some members of the scientific community, simply because the database is 'well known' and of an easier access than the original literature (see Dubois \& Raffaëlli 2009: 23-25).

In fact, as long as we do not have a comprehensive and reliable nomenclatural database, it may be aptly considered premature and little useful to embark into the enormous work of working on taxonomic databases that will partly be built on sand and anyway are bound to change regularly as phylogenetic and taxonomic research progresses. Much time and energy would indeed be saved in ignoring in a first step the taxonomic information attached to the nomina (e.g., the fact that they are considered valid or not, and by which authors), and to concentrate on the building of a serious, professional electronic nomenclatural database, as was the Neave in its time when computer did not exist. This could be only the result of a collective endeavour. Such a database could in the long run concern all zoological nomina of all nominal-series. But for the time being, much more information is available in the existing websites about genus-series nomina than about the other ones, so it would appear to be feasible, if the international community was able to mobilise for this purpose, to build an 'improved' Nomenclator Zoologicus of the $21^{\text {st }}$ century for genus-series nomina.

To be fully useful to working taxonomists, such a database should include all the information necessary to know the nomenclatural (not taxonomic) status of all zoological generic and subgeneric nomina: [I1] the complete original reference of the nomen; [I2] whether the nomen is available or not, and if not the reason for its unavailability; [I3] the original spelling(s) of 
the nomen; [I4] if relevant, reference to the first-reviser action that chose the 'correct original spelling' among 'multiple original spellings'; [I5] the grammatical gender of the nomen and the kind of evidence used to establish it; [I6] the type-species of the genus or subgenus, given with its mode of designation (see Dubois 2011a: 52-53) with if relevant the complete reference to the subsequent designation, and not simply as a 'fact' like in most databases and synonymies, as this information may be difficult to establish and may be wrong if first-reviser actions have been missed; [17] if relevant, the existence of senior and junior homonyms of the nomen; [I8] if relevant, the fact that the nomen is a neonym (either a nomen novum or an unjustified emendation) or an archaeonym of another nomen; [19] if relevant, the existence of other objective synonyms of the nomen (beside archaeonyms or neonyms); [I10] if relevant, the existence of a justified emendation of the nomen with its complete reference; [I110] if relevant, mention of any decision taken by the Commission under its Plenary Powers that affects the nomenclatural status of this nomen with its complete reference.

\section{Synonymy}

The general term 'synonymy', which designates the fact that two distinct nomina designate the same taxon, covers two very distinct situations. Objective synonyms (isonyms; Dubois 2000), based on the same onomatophore ('name-bearing type'), are nomenclatural synonyms and remain so forever, despite possible changes in the classification, whereas subjective synonyms (doxisonyms; Dubois 2000), based on different onomatophores, are taxonomic and labile, being liable to apply to different taxa if the classification changes. Some debutant taxonomists think that, once a nomen has been 'synonymised', it has been so to say 'nullified' and withdrawn from the field of zoological nomenclature, as if it had 'lost its availability'. This is of course not true, as even if considered an invalid synonym in a given classification, it remains available and may be reinstated as valid if the classification changes. Unfortunately, the Code itself seems to support this erroneous interpretation in its Article 23.9.1.1 which allows to reject as permanently invalid a senior synonym which "has not been used as a valid [emphasis mine] name after 1899", which means that a nomen that has been cited hundreds of times as an invalid synonym in synonymic lists, or considered as a senior homonym invalidating (a) junior one(s), may be rejected under this Article as a 'nomen oblitum', which is absurd: of course this Article should be corrected by replacing the term 'valid' by the term 'available'.

Whenever erecting a new genus or subgenus, and before even thinking of coining a new nomen for it, a taxonomist should therefore check whether there exists already an available nomen that applies to this taxon-i.e., the 'type species' of which belongs in the newly recognised taxon. For failing to do this, the risk exist to create a junior objective or subjective synonym of it. This situation is common enough in recent taxonomic publications to justify raising this bell.

The search for potential nomina that might apply to the new taxon should not be limited to the synonymy of the generic nomen or nomina under which the species of the new taxon were so far known. It should also include the synonymies of 'not so closely related' genera, as well as genus-series nomina of the group at stake so far considered incertae sedis. This is because taxonomy is not a 'frozen' science which would only include 'additions' of new taxa and 'subtraction' of others through synonymisation. Taxa are concepts, or hypotheses, that can be modified every time new specimens, new characters, new techniques and methods, or new analyses are taken into account. Taxa are not 'essences' that would be defined once and for 
all, but each of them expresses a hypothesis or a theory concerning the relationships between the organisms studied: thus any erection of a new taxon involves in fact a (often untold) 'redefinition' of all other related taxa. Any description of a new genus, even if not included formally in a larger revision of a more inclusive taxon (e.g., a tribe, subfamily or family), relies in fact on a new interpretation of the taxonomic relationships between the members of the new taxon and those of related taxa: in other words, if it is a serious taxonomic work, it in fact amounts to a 'mini-revision' of its immediately superordinate taxon, so that a survey of all the available nomina in the group should precede any proposition of a new nomen.

In case a new nomen is proposed for a taxon for which an older nomen was already available, the correction should be published as soon as possible by any taxonomist discovering the mistake, before it is repeated and becomes 'entrenched in the taxonomic literature'.

\section{Neonymy}

As we have seen, genus-series nomina that are strictly identical in spelling are homonyms, and the junior one is permanently invalid. When erecting a new genus or subgenus, a taxonomist may find that a nomen is already available for this taxon but is a junior homonym. In such a case, and if no other junior nomen is available for this taxon, rather than proposing a new nominal taxon, a parsimonious solution may be to propose a neonym (nomen novum, new replacement nomen) for this junior homonym - caring for it not to be itself a junior homonym. This solution is parsimonious in the sense that the neonym has the same onomatophore ('type species') as its archaeonym and that there is no need to write a new diagnosis to make it available: it can be made available in a very short paper of a few lines that can be published very quickly.

For this procedure to be valid, however, the replaced homonym (archaeonym) must be itself duly available. A neonym proposed for an unavailable nomen is itself unavailable, as in the case of the nomen [N8] above.

On the other hand, a neonym proposed unnecessarily for an available nomen that is not a junior homonym, although being indeed available, cannot be valid and will stand as a junior isonym of the replaced nomen, as in the case of the nomen [N10] above.

A useful guideline when introducing a genus-series neonym is to afford it the same grammatical gender as its archaeonym: this will avoid to have to change the endings of some terminal epithets of some of the species and subspecies included in the genus, and consequently the mistakes that not rarely creep into this process when made by authors who do not have a good knowledge of Latin language. This recommendation which is just based on common sense is similar to that given elsewhere for the erection of new subgenera in genera (Dubois \& Raffaëlli 2009: 21-22), but unfortunately many authors do not follow this simple precaution.

A last warning on this matter concerns the terminology. The Code uses two different designations for the concept just discussed: 'nomen novum' and 'new replacement name'. They are treated as synonyms in the Code although strictly speaking, if the terms that compose them are considered, the second one is more informative than the former and not equivalent to it. The Code does not propose a term for the nomen that has been replaced, which sometimes requires to write awkward sentences to designate this concept: the terms 
neonym and archaeonym (Dubois 2000, 2006) allow to fill this void. Besides these terms, the current Code uses the term 'substitute name' for any nomen, whether already existent or new, used to replace a junior homonym. According to Article 60.3, 'new substitute names' may be either neonyms or idionyms (new term introduced here, derived from classic Greek 'i $\delta 10 \varsigma$, idios, 'particular, proper' and övo $\mu \alpha$, onoma, 'name', and meaning 'brand new nomen, not proposed to replace an existing one'). This term 'substitute name' is prone to provoke confusion. It resembles the terms 'avowed substitute' used in the botanical Code (McNeill et al. 2012) as a synonym of nomen novum, as well as the term nomen substitutum which has long been used in zoological nomenclature for the concept of nomen novum or neonym. As a consequence, some zoologists still use the term 'substitute name' in the latter sense, which is incorrect (see e.g. Dubois \& Frétey 2016). The use of the term diadochonym (Dubois 2012) for the concept called 'substitute name' in the current Code allows to avoid such confusions.

\section{Length and palatability of nomina}

The Code does not provide any prescription regarding the length of nomina. Regarding genusseries nomina, Article 11.8 just writes that they must be words of two or more letters which must be, or must be treated as, nouns in the nominative singular. Recommendation $25 \mathrm{C}$ adds in this respect: "Authors should exercise reasonable care and consideration in forming new names to ensure that they are chosen with their subsequent users in mind and that, as far as possible, they are appropriate, compact, euphonious, memorable, and do not cause offense." The same ideas are repeated slightly differently in the 'General recommendations' that appear in Appendix B of the Code: "New names (...) should be euphonious and easily memorable". These are just Recommendations, not Rules, and concepts like 'euphonious' and 'easily memorable' are very relative, depending on the culture and language of persons. The term 'compact' is not very explicit, but it seems to mean 'occupying a small space', in other words 'short'. This point has not been very much addressed in the taxonomic literature. Dubois \& Raffaëlli (2009: 17-22) argued in detail why, in their opinion, "zoological nomina should be short and simple" and recommended as a 'rule of thumb' that generic and other nomina should include a maximum of 8-12 letters (preferably less) arranged in 4-5 syllables (preferably less). Dubois (2010: 14-18, 21-24, 2011a: 45-48) provided more examples and arguments, and wrote: "Scientific nomina should be an aid to communication, not a brake to $i t$. The Recommendations of the Code should strongly urge taxonomists to stop coining long, unpalatable and pedant nomina, and to use short, euphonious and original nomina, as these will appear in several, many or, who knows, thousands of publications after their creation" (Dubois 2011a: 48). This is particularly true of genus-series nomina, which, sometimes long after their creation, may happen to become the stems of family-series nomina: long, cumbersome and unpalatable genus-series nomina will result in even longer family-series, which will be even more cumbersome and unpalatable and will not comply with the recommendation that they should have been "chosen with their subsequent users in mind".

\section{Discussion and conclusion}

This discussion started with several examples of nomenclatural errors regarding generic nomina in the recent literature. The orthopteran nomina 'Walkerella' Otte \& Perez-Gelabert, $2009 a$ and 'Walkerana' Otte \& Perez-Gelabert, 2009b were shown to be unavailable for being nomina nuda. Consequently, the amphibian nomen Walkerana Dahanukar et al., 2016a is not 
invalid for being a junior homonym, and its replacement by Sallywalkerana Dahanukar et al., $2016 b$ was unjustified and should not be followed. These recent examples of nomenclatural errors in generic nomenclature are just a few among many in recent publications that could be cited and analysed.

Various methodological recommendations were offered above to try to avoid the introduction of nomenclatural mistakes when proposing new generic nomina in zootaxonomy. Following these recommendations as strictly as possible should reduce, if not completely avoid, the publication of such errors, which require the subsequent publication of corrections and therefore generate nomenclatural instability, sometimes immediately after the original publication where a new generic nomen was proposed.

As shown above, because of the incompleteness of the nomenclatural information easily accessible in paper or electronic databases (concerning not only the mere existence of earlier nomina but also their nomenclatural status regarding their availability and onomatophore), errors remain possible even if a serious methodology like that described above is followed. In this respect, taxonomists can benefit from advice and information from their peers, especially if these have a good knowledge of the taxonomic literature of the zoological group at stake, but also of nomenclatural Rules and their numerous traps and tricks. This advice can be seeked by asking knowledgeable colleagues to read the manuscript before submission, but also through the review process after submission. But as taxonomy is a field that many editors and referees do not master at all or master only approximately (see e.g. Dubois 2003), the choice of the journal and/or editor to which such a manuscript is submitted is a crucial one.

We have seen already that, for the time being at least (i.e., until the Rules for the electronic publication of nomenclatural acts proposed in the 2012 Amendment are not drastically improved), it is highly preferable to publish papers containing nomenclatural novelties in journals published on paper (with or without a simultaneous online distribution). Additional recommendations can be offered regarding the choice of the journal or book to which a manuscript will be submitted. Generalist biological journals should clearly be avoided for such publications, because, even when they have a 'high reputation', they very seldom submit the manuscripts which include nomenclatural acts to referees competent in zoological nomenclature, as was shown repeatedly in the recent years (e.g., Dubois 2003; Dubois et al. 2013). Journals specialised in zootaxonomy are often a better choice, but here also caution must be in order. Most 'famous' taxonomic journals, especially those publishing high numbers of papers in many zoological groups, regularly publish nomenclatural errors, some benign (e.g., concerning the derivation, spelling and grammatical gender of new nomina), some more severe (e.g., new generic nomina proposed without diagnosis in words or without designation of type species, or without the express mention that they are new nomina). In this respect, an important factor of the quality of the editorial work on a manuscript having nomenclatural implications is in the hands of the chief editor of the journal, or of the corresponding editor in charge of a manuscript. It is not enough to be a 'recognised specialist' of the zoological group involved to be a good editor or referee for papers having nomenclatural implications, especially when complex nomenclatural situations are at stake. It may therefore be useful to look at the past achievements of these persons before entrusting them the responsibility of caring for the review of a manuscript and the final editorial decisions about it, and it is prudent to avoid submitting such a manuscript to an editor who has already accepted to publish several indisputable nomenclatural errors. It may often be much wiser to choose a modest 'naturalist' journal published on paper and edited by a careful and experimented taxonomist with a good mastering of nomenclatural matters than to a more 
renowned journal in which the paper may end in the hands of careless or incompetent referees and editor.

\section{Acknowledgements}

I am grateful to Laure Desutter (Paris), Thierry Frétey (Saint-Maugan), Annemarie Ohler (Paris) and Jean-Yves Rasplus (Montferrier-sur-Lez) for providing me information and comments that were useful for this work, and to Alessandro Minelli (Padova) and two anonymous reviewers for their suggestions concerning the original manuscript.

\section{References}

Anonymous [International Commission on Zoological Nomenclature] (1999) International code of zoological nomenclature. Fourth edition. London (International Trust for zoological Nomenclature): i-xxix + 1-306.

Anonymous [International Commission on Zoological Nomenclature] (2012) Amendment of Articles 8, 9, 10, 21 and 78 of the International Code of Zoological nomenclature to expand and refine methods of publication. Bulletin of zoological nomenclature, 69 (3): 161-169.

Alonso-Zarazaga, M. A. \& Lyal, C. H. C. (1999) A world catalogue of families and genera of Curculionoidea (Insecta: Coleoptera) (excepting Scolytidae and Platypodidae). Barcelona (Entomopraxis): 1-315.

Ashlock, P. D. (1971) Monophyly and associated terms. Systematic Zoology, 20: 63-69.

Ashlock, P. D. (1985) A revision of the Bergidea group: a problem in classification and biogeography. Journal of the Kansas entomological Society, 27: 675-688.

Bauer, L. (1985) Considerations about Rana with a proposal of new genera. / Overpeinzingen betreffende Rana met een voostel van nieuwe genusnamen. Ripa, 1 November 1985: 1-9 + N1-N7.

Boulenger, G. A. (1882) Catalogue of the Batrachia Salientia s. Ecaudata in the collection of the British Museum. Second edition. London (Trustees of the British Museum, Natural History): i-xvi + 1-503, pl. 130.

Boulenger, G. A. (1920) A monograph of the South Asian, Papuan, Melanesian, and Australian frogs of the genus Rana. Records of the Indian Museum, 20: 1-226.

Curtis, J. (1837) Psocus fenestratus. In: J. Curtis, British Entomology; being illustrations and descriptions of the genera of Insects found in Great Britain and Ireland: containing coloured figures from nature of the most rare and beautiful species, and in many instances of the plants upon which they are found, Vol. 4, Hymenoptera, Part 2, Neuroptera, Trichoptera, London (Ellis \& Co.): 648-649, 1 pl.

Dahanukar, N., Modak, N., Krutha, K., Nameer, P. O., Padhye, A. D. \& Molur, S. (2016a) Leaping frogs (Anura: Ranixalidae) of the Western Ghats of India: an integrated taxonomic review. Journal of threatened Taxa, 8 (10): 9221-9288.

Dahanukar, N., Modak, N., Krutha, K., Nameer, P. O., Padhye, A. D. \& Molur, S. (2016b) Sallywalkerana, a replacement name for Walkerana Dahanukar et al. 2016 (Anura: Ranixalidae). Journal of threatened Taxa, 8 (11): 9381.

Dalla Torre, C. G. de (1898) Catalogus hymenopterorum hucusque descriptorum systematicus et synonymus. Volumen 5. Chacididae et Proctotrupidae. Lipsiae (Sumptibus Guilelmi Engelmann): [i-iii] + 1-598.

Dalman, J. V. (1820) Försök till Uppställning af Insect-familjen Pteromalini, i synnerhet med afseende på de i Sverige funne Arter. Kongliga Vetenskaps Academiens Handlingar, 1820: 123-174 + 177-182 + [i].

Dubois, A. (1986) Diagnose préliminaire d'un nouveau genre de Ranoidea (Amphibiens, Anoures) du sud de l'Inde. Alytes, 4 (3): 113-118.

Dubois, A. (1987a) Miscellanea taxinomica batrachologica (I). Alytes, '1986', 5 (1-2): 7-95.

Dubois, A. (1987b) Miscellanea nomenclatorica batrachologica (XV). Alytes, 5 (4): 175-176.

Dubois, A. (1988) The genus in zoology: a contribution to the theory of evolutionary systematics. Mémoires du Muséum national d'Histoire natuelle, (A), 140: 1-123.

Dubois, A. (2000) Synonymies and related lists in zoology: general proposals, with examples in herpetology. Dumerilia, 4 (2): 33-98.

Dubois, A. (2003) The relationships between taxonomy and conservation biology in the century of extinctions. Comptes rendus Biologies, 326 (suppl. 1): S9-S21. 
Dubois, A. (2004) Developmental pathway, speciation and supraspecific taxonomy in amphibians. 2. Developmental pathway, hybridizability and generic taxonomy. Alytes, 22 (1-2): 38-52.

Dubois, A. (2005) Proposed Rules for the incorporation of nomina of higher-ranked zoological taxa in the International Code of Zoological Nomenclature. 1. Some general questions, concepts and terms of biological nomenclature. Zoosystema, 27 (2): 365-426.

Dubois, A. (2006) Proposed Rules for the incorporation of nomina of higher-ranked zoological taxa in the International Code of Zoological Nomenclature. 2. The proposed Rules and their rationale. Zoosystema, 28 (1): $165-258$.

Dubois, A. (2008) Phylogenetic hypotheses, taxa and nomina in zoology. In: A. Minelli, L. Bonato \& G. Fusco (ed.), Updating the Linnaean heritage: names as tools for thinking about animals and plants, Zootaxa, 1950: 51-86.

Dubois, A. (2010) Describing new species. Taprobanica, 2 (1): 6-24.

Dubois, A. (2011a) The International Code of Zoological Nomenclature must be drastically improved before it is too late. Bionomina, 2: 1-104.

Dubois, A. (2011b) A zoologist's viewpoint on the Draft BioCode. Bionomina, 3: 45-62.

Dubois, A. (2012) The distinction between introduction of a new nomen and subsequent use of a previously introduced nomen in zoological nomenclature. Bionomina, 5: 57-80.

Dubois, A. (2015) The Duplostensional Nomenclatural System for higher zoological nomenclature. Dumerilia, 5: $1-108$.

Dubois, A. (2017) The nomenclatural status of Hysaplesia, Hylaplesia, Dendrobates and related nomina (Amphibia, Anura), with general comments on zoological nomenclature and its governance, as well as on taxonomic databases and websites. Bionomina, 11: 1-48.

Dubois, A. \& Aescht, E. (ed.) (2016) LZC Session 6. Proposal AVA-01. Observatory on Availability in Zoological Nomenclature. Dumerilia, 6: 62-70.

Dubois, A., Crochet, P.-A., Dickinson, E. C., Nemésio, A., Aescht, E., Bauer, A. M., Blagoderov, V., Bour, R., de Carvalho, M. R., Desutter-Grandcolas, L., Frétey, T., Jäger, P., Koyamba, V., Lavilla, E. O., Löbl, I., Louchart, A., Malécot, V., Schatz, H. \& Ohler, A. (2013) Nomenclatural and taxonomic problems related to the electronic publication of new nomina and nomenclatural acts in zoology, with brief comments on optical discs and on the situation in botany. Zootaxa, 3735 (1): 1-94.

Dubois, A. \& Frétey, T. (2016) A new nomen for a subfamily of frogs (Amphibia, Anura). Dumerilia, 6: 17-23.

Dubois, A., Frétey, T. \& Ohler, A. (2016) The nomenclatural status of the amphibian nomina published by Luuc Bauer from 1985 to 1994, with comments on the Rules of the Code concerning the techniques of printing. Bionomina, 10: 22-54.

Dubois, A. \& Raffaëlli, J. (2009) A new ergotaxonomy of the family Salamandridae Goldfuss, 1820 (Amphibia, Urodela). Alytes, 26 (1-4): 1-85.

Gorochov, A. V. (1986) On system and morphological evolution of the cricket family Gryllidae (Orthoptera) with description of new taxa. Communication 1. Zoologicheskiy Zhurnal, 65 (4): 516-527. [In Russian].

Günther, A. (1876) Third report on collections of Indian reptiles obtained by the British Museum. Proceedings of the zoological Society of London, 1875: 567-577.

Haliday, A. H. (1833) Essay on the classification of the parasitic Hymenoptera of Britain, which correspond with the Ichneumones minuti of Linnaeus. The entomological Magazine, 1: 259-276 + 333-350.

Hennig, W. (1950) Grundzüge einer Theorie der phylogenetischen Systematik. Berlin (Deutscher Zentralverlag): i-vii + 1-370.

Heraty, J. M., Burk, R. A., Cruaud, A., Gibson, G. A. P., Liljeblad, J., Munro, J., Rasplus, J.-Y., Delvare, G., Jansta, P., Gumovsky, A., Huber, J., Woolley, J. B., Krogmann, L., Heydon, S., Polaszek, A., Schmidt, S., Darling, D. C., Gates, M. E., Mottern, J., Murray, E., DalMolin, A., Triapitsyn, S., Baur, H., Pinto, J. D., van Noort, S. \& Yoder, M. (2013) A phylogenetic analysis of the megadiverse Chalcidoidea (Hymenoptera). Cladistics, 29: 466-542.

Huber, J. T. (2005) The gender and derivation of genus-group names in Myrmaridae and Mymarommatidae (Hymenoptera). Acta Societatis zoologicae bohemoslovenicae, 69 (1-2): 167-183.

Laurent, R. F. (1986) Sous-classe des Lissamphibiens (Lissamphibia). Systématique. In: P.-P. Grassé \& M. Delsol (ed.), Traité de Zoologie, 14, Amphibiens, fasc. I-B, Paris (Masson): 594-796.

Linnaeus, C. (1758) Systema Naturae per regna tria naturae, secundum classes, ordines, genera, species, cum characteribus, differentiis, synonymis, locis. Editio decima, reformata. Tomus 1. Holmiae (Laurentii Salvii): $[\mathrm{i}-\mathrm{iv}]+1-824$.

Lubbock, J. (1864) On two aquatic Hymenoptera, one of which uses its wings for swimming. The Transactions of the Linnean Society of London, 24: 135-142, pl. 23.

Ma, Y.-C., Peng, Y.-Q. \& Yang, D.-R. (2013) Description of two new species of Walkerella (Pteromalidae, Otitesellinae) from China with a key to the species of the genus. Zootaxa, 3702 (5): 473-482. 
McNeill, J., Barrie, F. R., Buck, W. R., Demoulin, V., Greuter, W., Hawksworth, D. L., Herendeen, P. S., Knapp, S., Marhold, K., Prado, J., Prud'homme van Reine, W. F., Smith, G. F., Wiersema, J. H. \& Turland, N. J. (ed.) (2012) International Code of nomenclature for algae, fungi and plants (Melbourne Code) adopted by the Eighteenth International Botanical Congress, Melbourne, Australia, July 2011. Rüggel (Gantner Verlag): i-xxx + 1-240.

Minelli, A. (1991) Biological systematics: the state of the art. London (Chapman \& Hall): $\mathrm{i}-\mathrm{xvi}+1-387$.

Neave, S. A. (Ed.) (1940) Nomenclator zoologicus. Vol. 4. Q-Z and supplement. London (Zoological Society of London): i-iv + 1-758.

Ohler, A. \& Dubois, A. (2012) Validation of two familial nomina nuda of Amphibia Anura. Alytes, 28 (3-4): $162-167$.

Otte, D. \& Perez-Gelabert, D. (2009a) Caribbean crickets. The Orthopterists Society: [i-iv] + 1-792.

Otte, D. \& Perez-Gelabert, D. (2009b) Caribbean crickets by D. Otte and D. Perez-Gelabert: corrections and synonymies and a note on the type of Gryllodes greenii Chopard (Orthoptera: Grylloidea). Transactions of the American entomological Society, 135 (4): 487-491.

Walker, F. (1846) List of the specimens of hymenopterous insects in the collection of the British Museum. Part I. Chalcidites. London (Trustees of the British Museum, Natural History): i-viii + 1-237.

Westwood, J. O. (1879) Descriptions of some minute hymenopterous insects. The Transactions of the Linnean Society of London, (2) (Zoology), 1 (8): 583-593, pl. 73.

Westwood, J. O. (1883) Further descriptions of insects infesting figs. Transactions of the entomological Society of London, 1883: 29-47, pl. 4-10.

Yoshimoto, C. M. (1990) A review of the genera of New World Mymaridae (Hymenoptera: Chalcidoidea). Flora \& Fauna Handbook, Gainesville, Florida (Sandhill Crane Press), 7: 1-176. 